\title{
Preparation of fat substitute based on the high-methoxyl pectin of citrus and application in moon-cake skin
}

\author{
Xinyu XU ${ }^{1} \mathbb{D}$, Huimin ZHANG ${ }^{1,2}$, Lin $\mathrm{LI}^{1,3}$, Lilan $\mathrm{SUN}^{1}$, Bin JIA ${ }^{1}$, Hujun YANG ${ }^{1}$, Feng ZUO ${ }^{1,2 *}$
}

\begin{abstract}
The high-methoxyl pectin of citrus was used to prepare a fat substitute and applied to the processing technology of moon-cake skin. The physical, chemical, and sensory properties of fat substitutes and prepared moon-cake skins were studied by selecting texture properties, rheological properties, water distribution, and water-holding capacity. Results showed that the gel hardness of glucan-sucrose (G-SG) (glucan/sucrose $=4: 6$ ) as synergistic gel was $6.23 \pm 0.10 \mathrm{~N}$, the elasticity was $3.97 \pm 0.03 \mathrm{~mm}$, the adhesive viscosity was $4.87 \pm 0.20 \mathrm{~N}$, the chewiness was $16.87 \pm 0.51 \mathrm{mj}$, the water-holding capacity was $98.33 \%$, and the gel obtained from sucrose (SG) as gelation agent had no significant difference $(\mathrm{P}>0.05)$. The consistency coefficient and thixotropic circle area of G-SG was larger than that of SG. Through dynamic viscoelastic scanning, we found that the tan $\delta$ of G-SG was smaller, and it had stronger hydrophobic interaction and stronger fluid properties after high-speed shear. It also more easily maintained a flow state similar to oil. G-SG was further applied to the processing technology of low-fat moon-cake skin. The color of the prepared low-fat moon-cake skin darkened, the water-holding capacity was enhanced, the fat content decreased from $22.21 \% \pm 0.54 \%$ to $14.07 \% \pm 0.57 \%$, the oil droplets enlarged, and flocculation strengthened. Results of texture-characteristic and sensory-score analyses showed no significant difference $(\mathrm{P}>0.05)$ from the control group when the oil substitution amount was $40 \%$. At this time, the total sensory score was $41.71 \pm 2.02$.
\end{abstract}

Keywords: high-methoxyl pectin of citrus; gel; fat substitute; moon-cake skin; sensory evaluation.

Practical Application: High-methoxyl citrus pectin widely exists in citrus peel, it has the characteristics of a wide range of sources, low price, and contains certain nutritional and health functions. Therefore, it has potential application prospects.In this study, high-methoxyl citrus pectin as a matrix was used to prepare fat substitutes, which can replace oil components in terms of texture and sensory. Using its high gelling properties to reduce the oil composition and maintain the palatability of the moon-cake, the low-fat moon-cake skin is developed. It can supply theoretical and technical basis for guiding the development of fat substitutes and low fat food.

\section{Introduction}

Pectin is extensively distributed in the primary cell wall and cell middle layer of plants. The content of pectin in citrus peel is rich, up to $30 \%-50 \%$, which is the main source of commercial pectin (Yan et al., 2021). Pectin is a kind of acidic heteropolysaccharide with a complex structure, primarily the polymerization of the $\alpha$-1,4-glycosidic bond-linked galacturonic acid cell. According to the degree of esterification, it can be divided into high-methoxyl pectin (HCP) and low-methoxyl pectin (Assoi et al., 2017). In the food industry, it is used to prepare pectin gel to enhance product quality because of its strong gel properties. However, the degree of esterification varies and some differences exist in the mechanism of gel formation. The gel formed by low-methoxyl pectin primarily depends on ion regulation, and $\mathrm{Ca}^{2+}$ combines with the carboxyl group on the molecular chain of low-methoxyl pectin to form an "egg box" mode. A lower degree of esterification means a closer bond and greater ease to form gel. The gel formed by HCP is affected mostly by hydrogen bonding and hydrophobic interaction.
At $\mathrm{pH}<3.5$, the gel formed by HCP is primarily affected by hydrogen bonding and hydrophobic interaction. The hydration molecules of high-concentration sucrose adsorbed onto the gap of the pectin network, and the undissociated carboxyl groups combined with hydroxyl groups through hydrogen bonds to form a compact three-dimensional network structure. Increasing the concentration of soluble solid benefited the formation of the gel network (Peng et al., 2020; Attallah \& Mamdouh, 2021).

With the improvements in human living standards, consumers increasingly pay attention to the nutrition and health of food while pursuing flavor. Pectin, as a fat substitute based on carbohydrates, can improve the structural characteristics of the aqueous phase and has strong water-holding capacity. As a fat substitute, pectin is extensively studied as an effective substitute for fat components in food. Maneerat et al. (2017) used banana peel to extract pectin and replace $30 \%$ of the fat in salad cream, thereby reducing the viscosity and brightness of salad cream. Microscopic imaging shows some flocculation of oil droplets, 
but no significant difference in texture and sensory acceptance of salad cream is observed. Méndez-Zamora et al. (2015) used different concentrations of inulin and pectin as fat substitutes to analyze the chemical composition, texture, and sensory score of frankfurter. They found that the water-holding capacity of low-fat sausage is improved, the yield is increased, and the color darkens. Structure and sensory evaluation results show that inulin and pectin could be used as fat substitutes in frankfurter. Zhang et al. (2018) extracted citrus pectin from canned wastewater and applied it to ice-cream processing. Low-fat ice cream with $45 \%$ lower oil content than the control group is obtained. No significant difference is observed in appearance, flavor, taste, and other quality. Thus, pectin has potential application prospect as a fat substitute in the food industry.

Moon cake originated in the Tang Dynasty and has a history of more than 1000 years in China. It is the most symbolic folk food of the Mid Autumn Festival (Chunli et al., 2008). However, the oil content of traditional moon cakes is high, reaching $20 \%-30 \%$. Heavy intake causes obesity, leading to diabetes, hyperlipidemia, arteriosclerosis, coronary heart disease, and other diseases (Abboud et al., 2020). Accordingly, reducing the oil composition on the premise of maintaining the palatability of moon cakes has become an urgent problem to be solved. Taking HCP as the research object, its rheological properties, texture properties, and scanning electron microscopy images were determined to analyze the fat substitutes under different conditions and texture and microstructure moon-cake skin. We aimed to provide a theoretical basis for HCP preparation as fat substitutes and for the research and development of low-fat moon-cake skin.

\section{Materials and methods}

\subsection{Test materials and reagents}

The HCP of citrus was from Yantai Andeli Pectin Co., Ltd. (Yantai, China). Citric acid, sucrose, starch, maltodextrin, and glucan were all food grade and obtained from Henan Sugar Cabinet Food Co., Ltd. (Henan, China).

\subsection{Test instruments}

The instruments used were as follows: TA-XT2i texture analyzer (Samat, USA); 5417R centrifuge (Eppendorf, Germany); DHR-1 rotary rheometer (TA Instruments, USA); FJ-200-SH homogenizer (Shanghai Shenlu Homogenizer Co., Ltd., China); S4800 field-emission scanning electron microscope (Hitachi, Japan); and NMI low-field magnetic resonance imaging instrument (Suzhou Newmark Analytical Instrument Co., Ltd., China).

\subsection{Test methods}

\section{Preparation of SG}

The optimum preparation process of citrus pectin gel was determined according to preliminary experiments. Initially, $1.5 \mathrm{~g}$ of pectin was dissolved in $30 \mathrm{~mL}$ of distilled water, heated at $80^{\circ} \mathrm{C}$ for $1 \mathrm{~h}$, and supplemented with water to maintain the sample concentration. The $\mathrm{pH}$ was adjusted to 2.51 with $12.5 \%$ citric acid and finally added with $7.13 \mathrm{~g}$ of sucrose. After mixing evenly, the mixture was left to stand for gelatinization.

\section{Selection of gelling agent}

Gels obtained from starch-sucrose, glucan-sucrose, and maltodextrin-sucrose were denoted as S-SG, G-SG, and M-SG, respectively.

\section{Texture characteristics of gels}

According to the test method of Moreira et al. (2014), the testing conditions of texture characteristics were as follows: AOAC $12.7 \mathrm{~mm}$ gel special cylindrical probe, the speed of front probe was $60 \mathrm{~mm} / \mathrm{min}$, the speed of probe was $60 \mathrm{~mm} / \mathrm{min}$, the speed of end probe was $60 \mathrm{~mm} / \mathrm{min}$, the deformation was $10 \%$, and the trigger force was 5 gf. Hardness, elasticity, stickiness, and chewiness were selected as the measuring indices.

\section{Rheological properties of gels}

The rheological properties of gels were determined based on the method of Abitbol et al. (2020) with slight modifications.

Static shear rheological properties Flat plate to flat plate measurement system was adopted. The plate diameter was $40 \mathrm{~mm}$, and the gap was $1 \mathrm{~mm}$. The citrus pectin gel samples were scooped out with a spoon and placed in the center of the rheometer plate. The silicone oil was coated around to prevent water evaporation. The scanning temperature was $25^{\circ} \mathrm{C}$, and the shear rate was $0-200 \mathrm{~s}^{-1}$. The power law model was used to regression fit the data points' shear stress and shear rate, and $\mathrm{R}^{2}$ was used to express fitting precision. The power-law equation was as follows (Equation 1):

$\tau=\mathrm{K} \gamma^{\mathrm{n}}$

$\tau$ - Shear stress / Pa;

$\mathrm{K}$ - Consistency coefficient / $\mathrm{Pa} \bullet \mathrm{s}^{\mathrm{n}}$;

$\gamma$ - Shear rate $/ \mathrm{s}^{-1}$;

$\mathrm{N}$ - fluid index, which represents the degree of deviation from Newtonian fluid.

\section{Static shear rheological properties}

At $25^{\circ} \mathrm{C}$, the scanning strain value was $0.5 \%$, and the oscillation frequency was set at $0.1-10 \mathrm{~Hz}$. Changes in the energy storage modulus G', energy-dissipation modulus $G^{\prime \prime}$, and loss tangent value $(\tan \delta)$ of pectin gel under this condition were measured.

\section{Water-holding capacity of gels}

Referring to the method of Schröder et al. (2004), the prepared gel system was placed in a $1 \mathrm{~mL}$ centrifuge tube. After centrifugation at room temperature for $45 \mathrm{~min}$ at $6000 \mathrm{r} / \mathrm{min}$, the top layer of water was collected, the mass was determined, and the water-holding capacity was calculated as follows (Equation 2): 
WHC $/ \%=\frac{m_{2}-m_{0}}{m_{1}-m_{0}} \times 100$

WHC - Water-holding capacity;

$\mathrm{m}_{0}$ - Mass of centrifuge tube with constant weight / g;

$\mathrm{m}_{1}$ - Total mass of centrifuge tube and sample before centrifugation / $\mathrm{g}$;

$\mathrm{m}_{2}$ - Mass of supernatant after aspiration / $\mathrm{g}$.

\subsection{Application of fat substitutes in moon-cake skin}

\section{Processing technology of moon cake}

Citrus pectin gel was microtreated with a homogenizer to obtain fat substitute. According to Zhang et al. (2018), some changes were made, and the prepared fat substitutes were used to replace $20 \%, 30 \%, 40 \%$, and $50 \%$ of the oil in the processing of moon-cake skin. The raw materials and addition amount of moon-cake skin are shown in Table 1. The processing flow of moon-cake skin is shown in Figure 1.

\section{Color}

According to the method of Maneerat et al. (2017), the color difference of five kinds of dried and crushed moon-cake skins was determined with a colorimeter.

\section{Texture characteristics}

This study aimed to explore the effect of different amounts of fat substitute on the texture characteristics of moon-cake skin According to the method of Singh et al. (2013), a P50 probe was selected. The probe speed was $60 \mathrm{~mm} / \mathrm{min}$ before measurement, $60 \mathrm{~mm} / \mathrm{min}$ during measurement, and $60 \mathrm{~mm} / \mathrm{min}$ at the end of measurement. The deformation was $10 \%$, and the trigger force was 5 gf. Hardness, elasticity, stickiness, and chewiness were selected as test indices.

\section{Low-field nuclear magnetic resonance (LF-NMR)}

The distribution of water and oil in moon-cake skin was determined by LF-NMR, in reference to the method of SánchezAlonso et al. (2014). The specimen was collected with a sampler and placed in a nuclear magnetic tube for determination. The parameters were as follows: half echo time, $150 \mu \mathrm{s}$; scanning times, 16; number of echoes, 3000; and repeated sampling interval, $3000 \mathrm{~ms}$. $\mathrm{T}_{2}$ images were obtained by NMR inversion fitting software.

\section{Scanning electron microscopy (SEM)}

According to the method of Güner et al. (2018), five kinds of dried and crushed moon-cake skin samples were fixed and sprayed with gold. Their surface structure characteristics were observed by SEM at $30 \times$ and 500 magnification.

\section{Sensory evaluation}

According to the method of Wang et al. (2020) with slight modifications, 50 sensory evaluators scored the shape, color, texture, taste, and flavor, as well as the impurities and overall acceptability, of the five groups of moon-cake skin. The highest score of each index was 10.0 points, and the lowest was 1.0 point. The weight coefficients of morphology, color, texture, taste, and flavor were 2.0, and the weight coefficients of impurities

Table 1. Raw materials and addition of low-fat moon-cake skin.

\begin{tabular}{|c|c|c|c|c|c|}
\hline \multirow{2}{*}{ Ingredient list } & \multicolumn{5}{|c|}{ Addition amount / g } \\
\hline & $\mathrm{C}$ & $\mathrm{T}_{1}$ & $\mathrm{~T}_{2}$ & $\mathrm{~T}_{3}$ & $\mathrm{~T}_{4}$ \\
\hline Low-gluten flour & 100 & 100 & 100 & 100 & 100 \\
\hline Oil & 30 & 24 & 21 & 18 & 15 \\
\hline Golden syrup & 20 & 20 & 20 & 20 & 20 \\
\hline Jianshui & 4 & 4 & 4 & 4 & 4 \\
\hline Egg liquid & 10 & 10 & 10 & 10 & 10 \\
\hline Fat substitutes & 0 & 6 & 9 & 12 & 15 \\
\hline
\end{tabular}

Note: $\mathrm{C}$ is the control group; and $\mathrm{T}_{1}, \mathrm{~T}_{2}, \mathrm{~T}_{3}$, and $\mathrm{T}_{4}$ are low-fat moon cakes replacing $20 \%, 30 \%, 40 \%$, and $50 \%$ of the oil components, respectively.

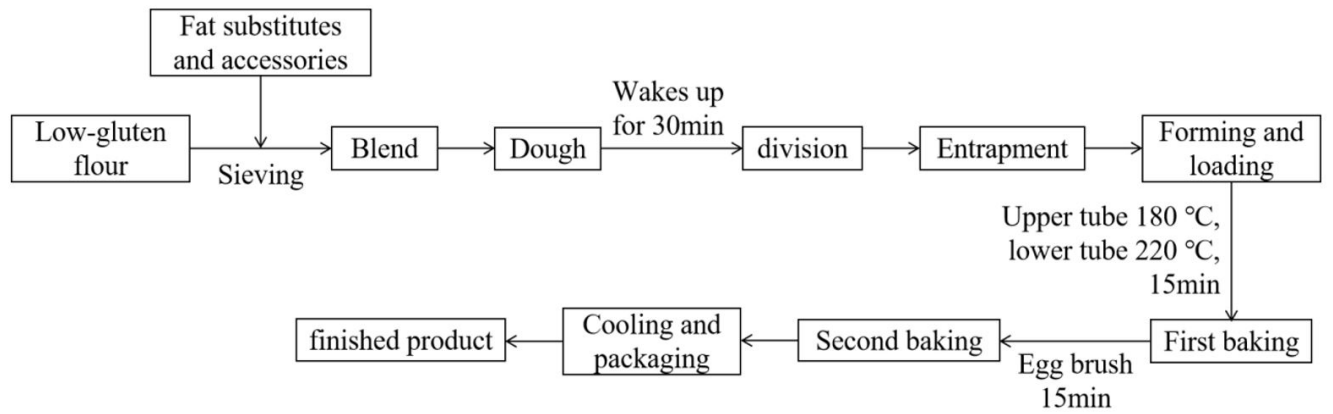

Figure 1. Processing technology of moon cake. 
and overall acceptability were 1.0. The total sensory score was obtained by adding the scores.

\section{Nutrients}

Protein content in low-fat moon-cake skin was determined according to the method specified in GB/T 5009.5-2016, and the protein-conversion coefficient was 6.25. Fat-content determination was conducted according to the method specified in GB/T 5009.6-2016. Ash content was determined according to the method specified in GB/T 5009.4-2016. Moisture content was determined according to the method specified in GB/T 5009.3-2016. Total sugar content was determined according to the method specified in GB/T 18738-2006.

\section{Statistical analysis}

All samples were set up three parallel, and data are expressed as the mean \pm standard deviation. Significant difference was determined by ANOVA $(\mathrm{P}<0.05)$. Drawing was performed with Origin 2018 64Bit and Excel.

\section{Results}

\subsection{Texture characteristics of gel formed by a synergistic gelation agent}

Adding too much sucrose to food can result in excessive heat and increase the risk of diabetes and obesity (Figueroa et al., 2018). The present study aimed to prepare a fat substitute based on citrus pectin. However, adding a large amount of sucrose into the preparation of citrus pectin gel was contrary to this purpose. Kim et al. (2020) reported that fat can inhibit the formation of protein network and produce soft texture by interacting with protein, whereas fat substitutes of carbohydrate matrix can form fat like texture by destroying the protein solid network. Starch, glucan, and maltodextrin were fat substitutes of the carbohydrate matrix, which can be absorbed by the human body without side effects. Therefore, starch, glucan, and maltodextrin were used as synergistic gelation agents. The gel formation of S-SG, G-SG, and M-SG is shown in Table 2. Starch, glucan, and maltodextrin can replace part of sucrose, and the maximum replacement amount can reach $10 \%, 60 \%$, and $50 \%$, respectively.

The texture characteristics of synergistic gelation agents S-SG, G-SG, and M-SG that can form gels were analyzed. Results are shown in Table 3.

For the gel formed by SG in the control group, compared with the gel formed by SG, the gel hardness, elasticity, stickiness, and chewiness of gel formed by the synergistic gelation agents S-SG and M-SG were lower, and the texture difference was significant $(\mathrm{P}<0.05)$. This finding was due to the substantial amylose content of the synergistic gelation agents S-SG and M-SG, which hindered the hydrogen bonding of the carboxyl and hydroxyl groups. Thus, forming a stable network structure was difficult.

\subsection{Rheological properties of gels}

The static-shear rheological curves of the synergistic gelation agents SG and G-SG are shown in Figure 2. The shear stress of two kinds of gels increased with increased shear rate. At the same shear rate, the shear stress of G-SG was higher than that of SG. Huang et al. (2020) reported that under the action of intermolecular force, with increased shear stress, the intermolecular crosslinking gradually tightened, and the intermolecular entanglement

Table 2. Gel formation of different gelling agents.

\begin{tabular}{ccccccc}
\hline Gel & $9: 21$ & $12: 18$ & $15: 15$ & $18: 12$ & $21: 9$ & - \\
S-SG & - & - & - & - & $24: 6$ & - \\
G-SG & - & + & + & + & + \\
M-SG & - & - & + & + & + \\
\hline
\end{tabular}

Note: The ratio in the table indicates the ratio of sucrose to synergistic gelation agent; "+" indicates that gel can form; and "-"indicates that gel cannot form.

Table 3. Effects of starch, glucan, and maltodextrin as synergistic gelation agent on the texture properties of pectin gel.

\begin{tabular}{|c|c|c|c|c|c|}
\hline Gel & Concentration ratio & Hardness /N & Elastic $/ \mathrm{mm}$ & Stickiness /N & Chewiness /mj \\
\hline SG & - & $6.54 \pm 0.22^{b}$ & $3.88 \pm 0.02^{\mathrm{d}}$ & $5.14 \pm 0.11^{b c}$ & $17.63 \pm 0.51^{b c}$ \\
\hline S-SG & $1: 9$ & $2.43 \pm 0.28^{\mathrm{e}}$ & $3.22 \pm 0.05^{\mathrm{gh}}$ & $1.58 \pm 0.10^{\mathrm{ef}}$ & $5.10 \pm 0.34^{\mathrm{f}}$ \\
\hline \multirow[t]{6}{*}{ G-SG } & $6: 4$ & $4.41 \pm 0.44^{\mathrm{c}}$ & $3.76 \pm 0.01^{\mathrm{e}}$ & $3.31 \pm 0.29^{\mathrm{d}}$ & $10.81 \pm 0.96^{\mathrm{d}}$ \\
\hline & $5: 5$ & $4.49 \pm 0.50^{c}$ & $3.84 \pm 0.03^{\mathrm{de}}$ & $3.40 \pm 0.40^{\mathrm{d}}$ & $10.68 \pm 1.36^{\mathrm{d}}$ \\
\hline & $4: 6$ & $6.23 \pm 0.10^{\mathrm{b}}$ & $3.97 \pm 0.03^{\mathrm{d}}$ & $4.87 \pm 0.20^{c}$ & $16.87 \pm 0.51^{\mathrm{c}}$ \\
\hline & $3: 7$ & $6.36 \pm 0.55^{\mathrm{b}}$ & $4.05 \pm 0.03^{c}$ & $5.42 \pm 0.35^{\mathrm{ab}}$ & $18.04 \pm 0.33^{\mathrm{abc}}$ \\
\hline & $2: 8$ & $6.81 \pm 0.58^{\mathrm{ab}}$ & $4.16 \pm 0.07^{\mathrm{b}}$ & $5.37 \pm 0.61^{\mathrm{ab}}$ & $18.41 \pm 0.50^{\mathrm{ab}}$ \\
\hline & $1: 9$ & $7.30 \pm 0.93^{\mathrm{a}}$ & $4.1 \pm 0.02^{\mathrm{a}}$ & $5.74 \pm 0.27^{\mathrm{a}}$ & $19.01 \pm 1.45^{\mathrm{a}}$ \\
\hline \multirow[t]{5}{*}{ M-SG } & $5: 5$ & $1.84 \pm 0.09^{\mathrm{ef}}$ & $3.15 \pm 0.03^{h}$ & $0.95 \pm 0.13^{\mathrm{gh}}$ & $2.99 \pm 0.43^{h}$ \\
\hline & $4: 6$ & $1.67 \pm 0.03^{\mathrm{f}}$ & $3.31 \pm 0.05^{\mathrm{g}}$ & $0.88 \pm 0.04^{\mathrm{h}}$ & $2.90 \pm 0.18^{\mathrm{h}}$ \\
\hline & $3: 7$ & $2.04 \pm 0.09^{\mathrm{ef}}$ & $3.18 \pm 0.09^{h}$ & $1.14 \pm 0.18^{\mathrm{fgh}}$ & $3.63 \pm 0.60^{\mathrm{gh}}$ \\
\hline & $2: 8$ & $2.28 \pm 0.28^{\mathrm{ef}}$ & $3.23 \pm 0.02^{\mathrm{gh}}$ & $1.42 \pm 0.19^{\mathrm{fg}}$ & $4.59 \pm 0.62^{\mathrm{fg}}$ \\
\hline & $1: 9$ & $3.14 \pm 0.14^{\mathrm{d}}$ & $3.56 \pm 0.09^{f}$ & $1.85 \pm 0.15^{\mathrm{e}}$ & $6.94 \pm 0.38^{\mathrm{e}}$ \\
\hline
\end{tabular}

Note: A significant difference exists between different small letters $(\mathrm{P}<0.05)$ 
reached the most stable state. This finding indicated that G-SG had a stronger hydrophobic interaction than SG and formed a more compact three-dimensional network structure.

The fitting parameters of citrus pectin gel power-law equation are shown in Table 4 . The $\mathrm{R}^{2}$ of the curve was greater than 0.99 , indicating that the two pectin gels were highly fitted to the power-law model. The fluid index (n) was less than 1, indicating that these two kinds of gels were pseudoplastic fluids, showing shear thinning properties. Compared with SG, the G-SG consistency coefficient K was larger. Huang et al. (2019) reported that the entanglement between pectin and MTGase can enhance the consistency of the system, indicating that the interlinking between glucoside bonds and pectin chains in dextran leads to the increase of gelation and the thickening of the system.

The area of the G-SG thixotropic loop was 1604.70, and the area of the SG thixotropic loop was 1090.38. Li et al. (2019) found that the area of the fusiform thixotropic ring in the gel system determines the energy required to destroy the gel-network structure. A larger area of the thixotropic ring corresponds with greater damage degree of the gel structure under shear force. Forming a new network structure was more difficult, and maintaining the shape similar to oil was easier. In this study, the thixotropic ring area of G-SG was much larger than that of SG, showing that G-SG was stable after being destroyed by shear force and was more suitable as a fat substitute.

The viscoelasticity of pectin gel can be reflected by dynamic rheological properties. The relationship between the energy storage modulus $\mathrm{G}^{\prime}$ and the energy dissipation modulus $\mathrm{G}^{\prime \prime}$ of

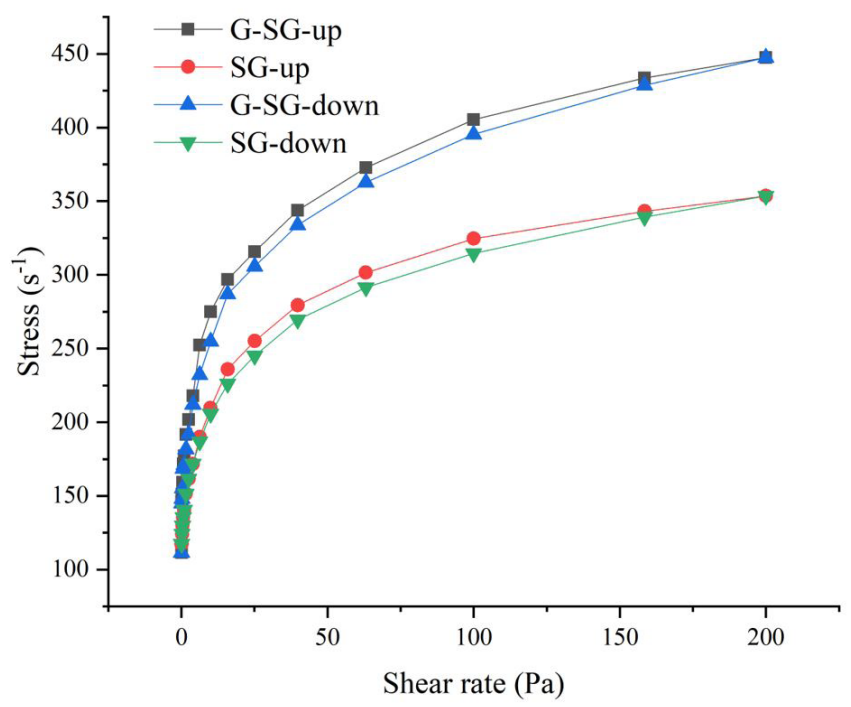

Figure 2. Static rheological curve of citrus pectin gel. pectin gel is shown in Figures $3 \mathrm{AB}$. The $\mathrm{G}^{\prime}$ of the two kinds of gels were larger than $\mathrm{G}^{\prime \prime}$ and increased with increased frequency. Haddad et al. (2019) studied pectin gel and found that when pectin gel $G^{\prime}$ is greater than $G^{\prime \prime}$, good frequency dependence is observed and pectin gel has good gel properties. This finding indicated that the gel prepared by G-SG and SG can form a dense three-dimensional network structure, but the $G^{\prime}$ and $G^{\prime \prime}$ of G-SG were all higher than those of SG. Thus, the gel rigidity and gel elasticity of G-SG were stronger than those of SG, the same as the results of gel-texture determination in the above. The relationship between the loss tangent $\left(\tan \delta=\mathrm{G}^{\prime} / \mathrm{G}^{\prime \prime}\right)$ of pectin gel and the frequency change is shown in Figure 3C. The tan $\delta$ of G-SG was less than that of SG. Zhang et al. (2020) studied the loss tangent of a pectin-cellulose gel system and found that the strong interaction between pectin and cellulose molecules enhances the three-dimensional network structure of the system. At this time, $\tan \delta$ decreases, and the system shows more elastic fluid quality. Thus, G-SG has stronger fluid properties.

\subsection{Analysis of water-holding capacity of gels}

Wan et al. (2019) reported that fat substitute can stabilize the mixture of oil and water, stabilize the bound water and other components in food, inhibit water loss, increase product consistency, and provide taste similar to fat. Therefore, the water-holding capacity of fat substitutes is also very important. Herein, the water-holding capacity of SG and G-SG was studied, and results are shown in Figure 4.

The water-holding capacities were $98.61 \% \pm 0.50 \%$ for SG and $98.33 \% \pm 0.91 \%$ for G-SG, with no significant difference. The water-holding power of the two gels was close. Li et al. (2018) found that the formation of a dense network structure in the gel could bind the water in the gel system, resulting in enhanced gel strength and water-holding capacity. Therefore, gel strength and gel water-holding capacity are positively correlated within a certain range. In the current work, G-SG had good gel properties and strong water-holding capacity. Thus, it can be used as a fat substitute and further applied to the substitution test of oil in moon-cake skin.

\subsection{Analysis of color of low-fat moon-cake skin}

Color analysis is an important analytical means of reflecting the hue and brightness of food (Gokcen et al., 2021). Herein, we replaced the oil composition and analyzed the color of the prepared low-fat moon-cake skin. Results are shown in Table 5. The brightness of low-fat moon-cake skin was weaker, and red and yellow were enhanced. A significant difference compared with the control group $(\mathrm{P}<0.05)$ was observed, indicating that the color of low-fat moon-cake skin darkened. The relative color difference $\left(\Delta E^{*}\right)$ calculated by the color change was greater than

Table 4. Fitting parameters of citrus pectin gel power-law equation.

\begin{tabular}{|c|c|c|c|c|c|c|c|}
\hline \multirow{2}{*}{ Gel } & \multicolumn{2}{|c|}{ Consistency coefficient $\mathrm{K}\left(\mathrm{Pa} \cdot \mathrm{s}^{\mathrm{n}}\right)$} & \multicolumn{2}{|c|}{ Fluid index $\mathrm{n}$} & \multicolumn{2}{|c|}{ Coefficient of determination $\mathrm{R}^{2}$} & \multirow{2}{*}{$\begin{array}{c}\text { Thixotropic area } \\
\left(\mathrm{Pa} \cdot \mathrm{s}^{-1}\right)\end{array}$} \\
\hline & Uplink & Downlink & Uplink & Downlink & Uplink & Downlink & \\
\hline G-SG & $181.67 \pm 2.15$ & $173.93 \pm 2.54$ & $0.17 \pm 0.00$ & $0.18 \pm 0.00$ & 0.996 & 0.994 & 1604.70 \\
\hline SG & $146.89 \pm 2.56$ & $145.24 \pm 2.37$ & $0.17 \pm 0.00$ & $0.17 \pm 0.00$ & 0.990 & 0.991 & 1090.38 \\
\hline
\end{tabular}


(A)

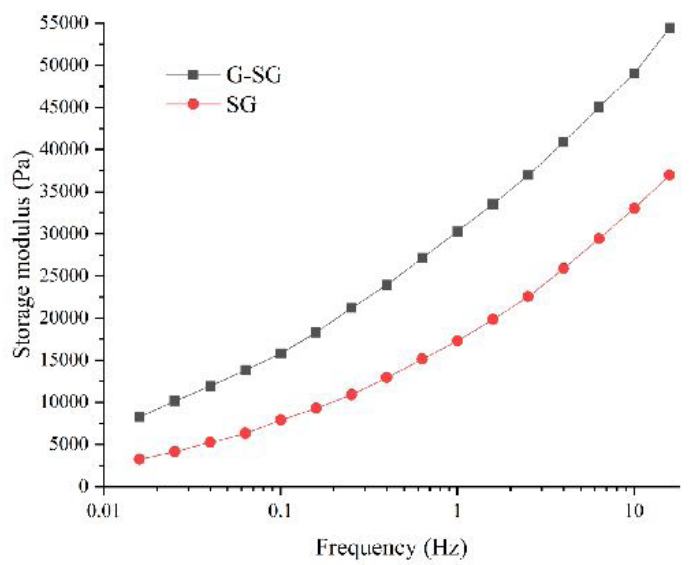

(C)

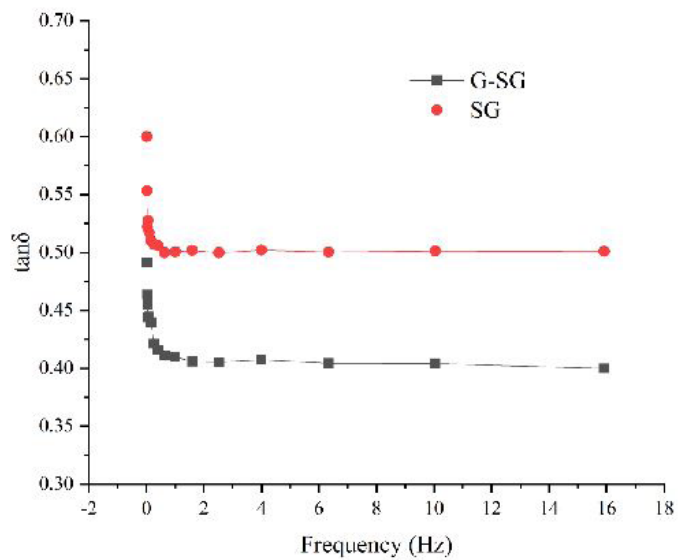

(B)

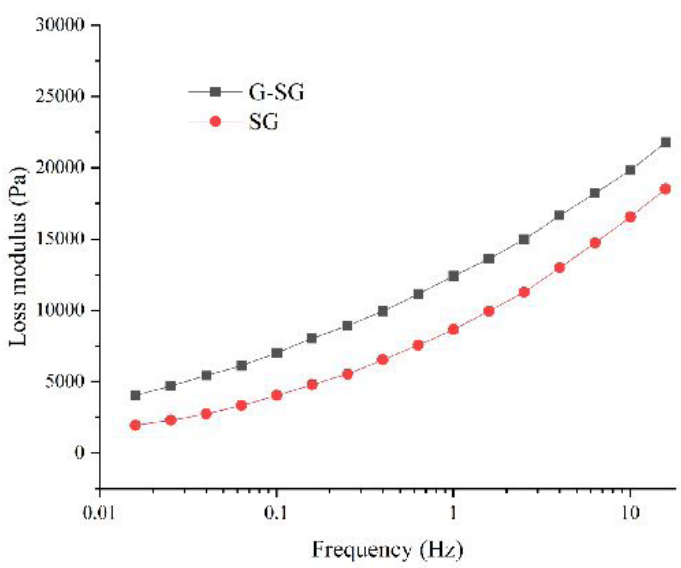

Figure 3. Dynamic viscoelastic curve (A, B) and tan $\delta$ value change curve (C) of HCP.

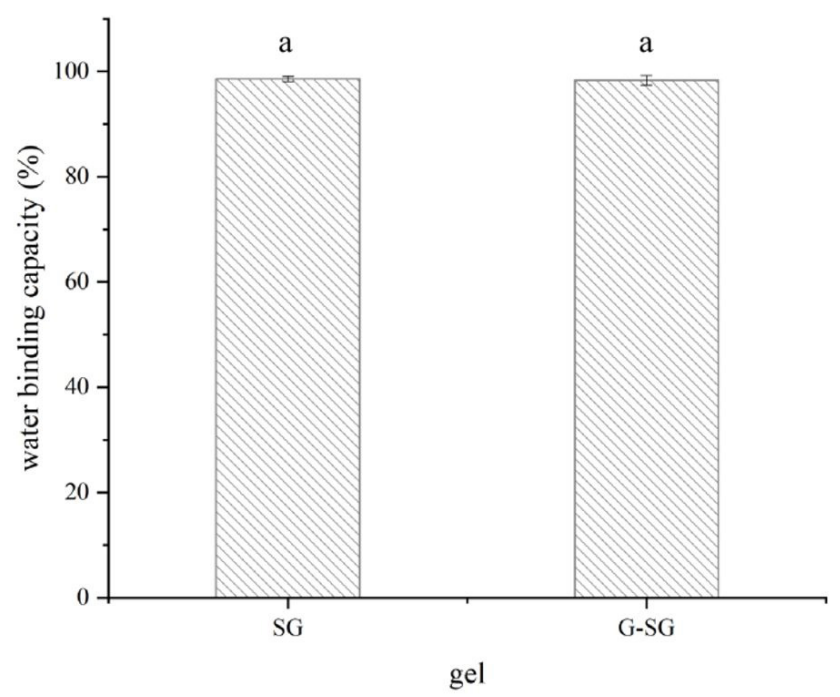

Figure 4. Gel water-holding capacity of HCP.

2 , indicating that a color difference existed between samples. This finding was due to the small amount of sucrose in fat substitutes, which increased the total sugar content of low-fat moon-cake skin. Consequently, the reactive carbonyl of sugar interacted with the nucleophilic amino group of amino acid, thereby promoting the occurrence of Maillard reaction (Ogutu et al., 2017).

\subsection{Analysis of texture characteristics of low-fat moon-cake skin}

The texture characteristics of low-fat moon-cake skin were measured, and results are shown in Table 5. With increased oil substitution, the hardness and stickiness of moon-cake skin gradually increased, whereas its elasticity and chewability decreased. This finding was due to the strong water-retention ability of the fat substitutes, which increased the viscosity of the system, generated large bubbles in the product, and increased the hardness (Liu et al., 2008). The increase in hardness reduced the product's palatability and ultimately reduced its elasticity and chewability. These findings were consistent with those of Kakino et al. (2017).

\subsection{SEM analysis of low-fat moon-cake skin}

SEM is a micro-imaging technique with strong stereoscopic sense to observe the surface ultrastructure of samples (Paşcalău et al., 2020). In this study, SEM was used to observe low-fat moon-cake skin and understand the flocculation of oil droplets. The scanning 
results are shown in Figure 5. The full spherical particles in Figure 5 were oil droplets evenly distributed throughout a large number of samples (Figures 5AF). The irregular flake particles were gelatinized starch particles (Figsures 5FJ) (Ajibade et al., 2019). Figures 5AE show that with increased oil substitution, the number of oil droplets in the sample gradually decreased, which was due to the decrease in oil addition. Moreover, the volume of oil droplets in the sample gradually increased and flocculation strengthened (Figures 5EJ). Günter (2020) proposed that flocculation can increase the effective volume fraction of emulsion and increase the viscosity of emulsion, indicating that flocculation is positively correlated with the stickiness of low-fat moon-cake skin, consistent with the above results.

Note: A-E are the SEM images of $\mathrm{C}, \mathrm{T}_{1}, \mathrm{~T}_{2}, \mathrm{~T}_{3}$, and $\mathrm{T}_{4}$ at $30 \times$ magnification, respectively; and $\mathrm{F}-\mathrm{J}$ are the SEM images of $\mathrm{C}, \mathrm{T}_{1}, \mathrm{~T}_{2}, \mathrm{~T}_{3}$, and $\mathrm{T}_{4}$ at $500 \times$ magnification.

\subsection{LF-NMR analysis of low-fat moon-cake skin}

LF-NMR technology is extensively used in food detection. By comparing the relaxation times $\mathrm{T}_{1}$ and $\mathrm{T}_{2}$, we determined oil content, water distribution, and water migration (Yu et al., 2021). Naho et al. (2021) divided the transverse relaxation time $\mathrm{T}_{2}$ into three parts, namely, $\mathrm{T}_{21}(0-10 \mathrm{~ms}), \mathrm{T}_{22}(10-100 \mathrm{~ms})$, and $\mathrm{T}_{23}$ (>100 ms), representing bound water, semi-bound water, and free water, respectively, to evaluate the water distribution of food. According to the transverse relaxation time $\mathrm{T}_{2}$ and peak intensity, the $\mathrm{T}_{2}$ inversion spectrum of LF-NMR of low-fat moon-cake skin was obtained, as shown in Figure 6. The water distribution obtained by calculation is shown in Table 6 .

Three peaks were observed for the control and experimental groups. The first and second peaks were those of $\mathrm{T}_{21}$ (bound water), and the third peak was that of $\mathrm{T}_{22}$ (semi-bound water). No free water was detected because the drying and grinding process before moon-cake skin detection caused the free water to evaporate. With increased oil substitution, the relaxation time decreased, $\mathrm{T}_{21}$ decreased from 7.05 to 4.04 , and $\mathrm{T}_{22}$ decreased from 49.77 to 37.65 . Wang et al. (2021) reported that the relaxation time $\mathrm{T}_{2}$ was affected by water fluidity, and the relaxation time $\mathrm{T}_{2}$ decreased with decreased water mobility. This finding indicated the weakening of the flow of free water and semi-free water in the low-fat moon-cake skin. With increased oil substitution, the peak areas of combined water and semi-combined water showed an overall upward trend, and the total peak area increased from $9737.14 \mathrm{~ms}^{2}$ to $20618.33 \mathrm{~ms}^{2}$, with significant difference $(\mathrm{P}<0.05)$. Accordingly, the total water content and water-holding capacity of low-fat moon-cake skin increased. The proportion of bound water peak decreased and the proportion of semi-bound water peak increased, and the difference was significant $(P<0.05)$. This finding was due to the enhanced water-holding capacity of low-fat moon-cake skin, which caused the content of bound water to almost remain unchanged and the content of semi-bound water to increase. Thus, the proportion of semi-bound water in the total peak area was higher. Overall, the LF-NMR results showed that a negative correlation existed between water fluidity and water-holding capacity, and that low-fat moon-cake skin had weaker water fluidity and stronger water-holding capacity.

\subsection{Sensory evaluation of low-fat moon-cake skin}

The sensory acceptance of low-fat moon-cake skin was scored, and results are shown in Table 7. Compared with the control group, no significant difference in sensory score existed when the amount of fat substitute was $40 \%(P>0.05)$. At this time, the total sensory score of low-fat moon-cake skin was $41.71 \pm 2.02$. When the amount of oil substitution was further increased to $50 \%$, the total sensory score decreased to $38.29 \pm 1.49$, and the scores of morphology, color, tissue, taste and flavor, and overall acceptance decreased and changed significantly $(\mathrm{P}<0.05)$.

Table 5. Determination of color and texture properties of low-fat moon-cake skin.

\begin{tabular}{|c|c|c|c|c|c|}
\hline Target & $\mathrm{C}$ & $\mathrm{T}_{1}$ & $\mathrm{~T}_{2}$ & $\mathrm{~T}_{3}$ & $\mathrm{~T}_{4}$ \\
\hline$L^{*}$ & $79.42 \pm 0.08^{a}$ & $77.64 \pm 0.88^{\mathrm{a}}$ & $75.50 \pm 1.40^{\mathrm{b}}$ & $73.45 \pm 0.48^{c}$ & $71.09 \pm 1.37^{\mathrm{d}}$ \\
\hline$a^{*}$ & $3.32 \pm 0.14^{\mathrm{a}}$ & $4.40 \pm 0.33^{\mathrm{b}}$ & $5.09 \pm 0.51^{\mathrm{b}}$ & $5.55 \pm 0.17^{\mathrm{c}}$ & $6.34 \pm 0.20^{\mathrm{d}}$ \\
\hline$b^{*}$ & $25.27 \pm 0.48^{\mathrm{a}}$ & $27.91 \pm 1.02^{\mathrm{a}}$ & $27.91 \pm 0.62^{\mathrm{ab}}$ & $28.42 \pm 0.49^{\mathrm{b}}$ & $28.79 \pm 0.38^{c}$ \\
\hline$\Delta E^{*}$ & $\mathrm{~N} / \mathrm{A}$ & $2.83 \pm 0.98^{\mathrm{a}}$ & $2.37 \pm 0.68^{\mathrm{a}}$ & $2.15 \pm 0.98^{\mathrm{a}}$ & $2.52 \pm 0.90^{\mathrm{a}}$ \\
\hline Hardness /N & $299.66 \pm 12.29^{b}$ & $305.02 \pm 12.58^{\mathrm{ab}}$ & $319.41 \pm 15.21^{\mathrm{ab}}$ & $322.14 \pm 11.55^{\mathrm{ab}}$ & $356.31 \pm 4.09^{\mathrm{a}}$ \\
\hline Elasticity $/ \mathrm{mm}$ & $7.21 \pm 0.11^{\mathrm{a}}$ & $7.15 \pm 0.08^{\mathrm{a}}$ & $7.00 \pm 0.02^{\mathrm{a}}$ & $7.08 \pm 0.07^{\mathrm{a}}$ & $6.93 \pm 0.06^{\mathrm{b}}$ \\
\hline Stickiness /N & $1.82 \pm 0.64^{\mathrm{b}}$ & $1.90 \pm 0.10^{\mathrm{b}}$ & $1.95 \pm 0.07^{\mathrm{b}}$ & $2.19 \pm 0.20^{\mathrm{ab}}$ & $2.48 \pm 0.09^{\mathrm{a}}$ \\
\hline Chewiness / $\mathrm{mj}$ & $297.55 \pm 9.25^{\mathrm{a}}$ & $292.45 \pm 8.03^{\mathrm{a}}$ & $288.98 \pm 11.39^{\mathrm{a}}$ & $280.44 \pm 15.69^{\mathrm{ab}}$ & $261.09 \pm 12.25^{t}$ \\
\hline
\end{tabular}

Table 6. Moisture distribution of low fat moon-cake skin.

\begin{tabular}{|c|c|c|c|c|c|c|c|c|}
\hline \multirow{2}{*}{ Group } & \multicolumn{4}{|c|}{$\mathrm{T}_{21}$} & \multicolumn{3}{|c|}{$\mathrm{T}_{22}$} & \multirow{2}{*}{ Total peak area $/ \mathrm{ms}^{2}$} \\
\hline & Peak area $/ \mathrm{ms}^{2}$ & Peak ratio /\% & Relaxat & $\mathrm{me} / \mathrm{ms}$ & Peak area $/ \mathrm{ms}^{2}$ & Peak ratio $/ \%$ & Relaxation time /ms & \\
\hline $\mathrm{C}$ & $407.40 \pm 9.82^{\mathrm{a}}$ & $4.18 \pm 0.05^{\mathrm{e}}$ & 0.57 & 7.05 & $9329.74 \pm 97.79^{a}$ & $95.82 \pm 0.05^{\mathrm{a}}$ & 49.77 & $9737.14 \pm 107.60^{\mathrm{a}}$ \\
\hline $\mathrm{T}_{1}$ & $468.58 \pm 3.65^{\mathrm{b}}$ & $3.13 \pm 0.07^{\mathrm{d}}$ & 0.50 & 6.14 & $14521.72 \pm 236.36^{\mathrm{b}}$ & $96.87 \pm 0.07^{\mathrm{b}}$ & 49.77 & $14490.30 \pm 232.77^{b}$ \\
\hline $\mathrm{T}_{2}$ & $526.45 \pm 10.47^{c}$ & $2.42 \pm 0.02^{\mathrm{b}}$ & 0.57 & 5.34 & $20734.46 \pm 520.12^{c}$ & $97.52 \pm 0.10^{\mathrm{d}}$ & 49.77 & $21260.91 \pm 511.71^{\mathrm{c}}$ \\
\hline $\mathrm{T}_{3}$ & $548.55 \pm 1.89^{\mathrm{d}}$ & $2.73 \pm 0.08^{c}$ & 0.57 & 5.34 & $20069.77 \pm 450.02^{c}$ & $97.34 \pm .07^{c}$ & 43.29 & $20618.33 \pm 448.36^{c}$ \\
\hline $\mathrm{T}_{4}$ & $479.39 \pm 12.38^{\mathrm{b}}$ & $1.95 \pm 0.02^{\mathrm{a}}$ & 0.57 & 4.04 & $24148.75 \pm 396.92^{\mathrm{d}}$ & $98.05 \pm 0.02^{\mathrm{e}}$ & 37.65 & $24628.15 \pm 409.27^{\mathrm{d}}$ \\
\hline
\end{tabular}


(A)

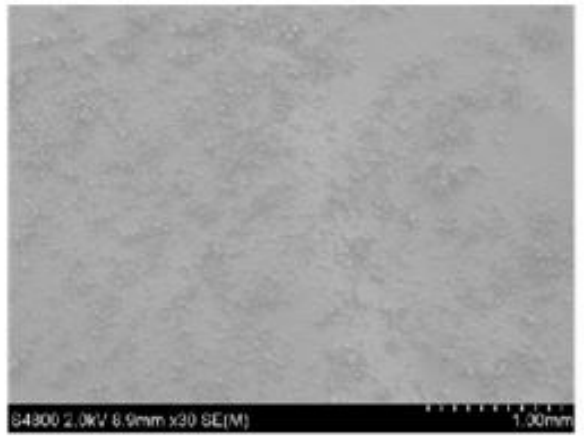

(B)

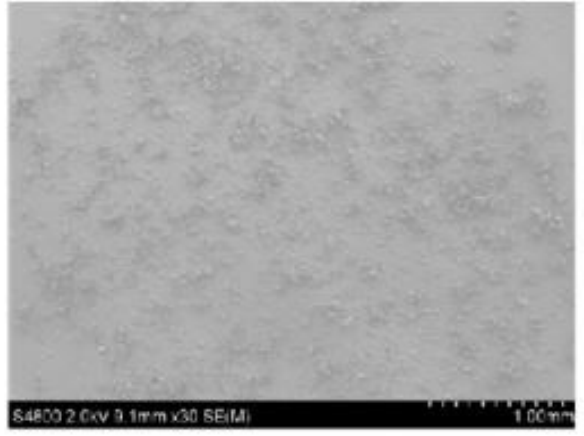

(C)

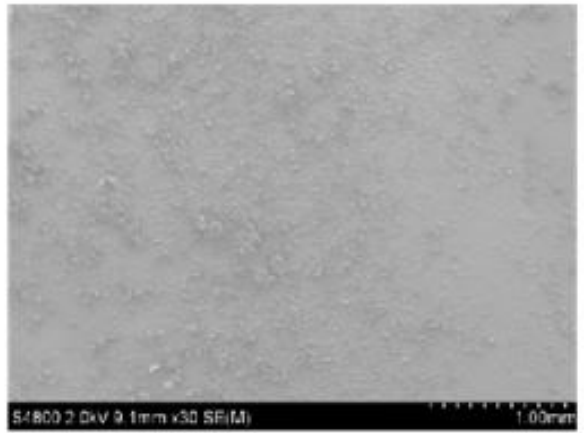

(D)

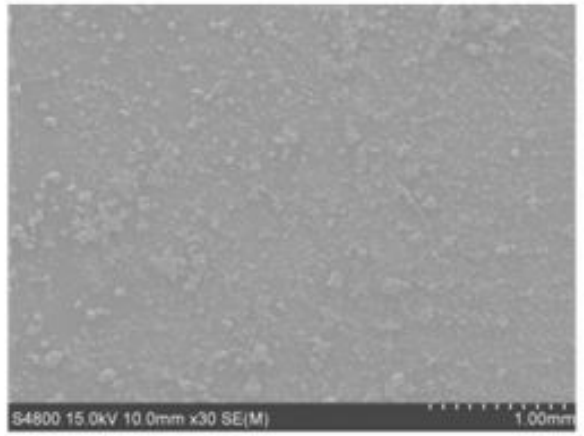

(E)

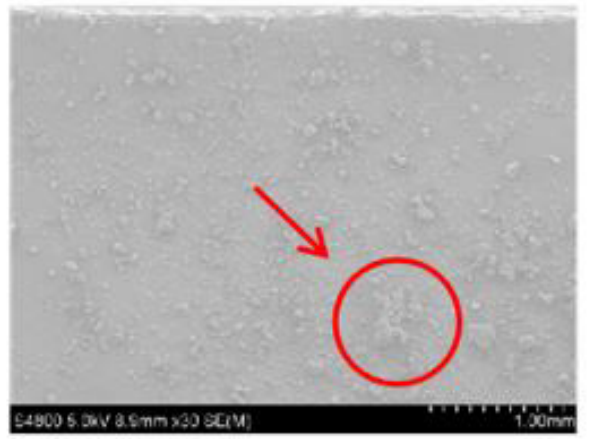

(F)

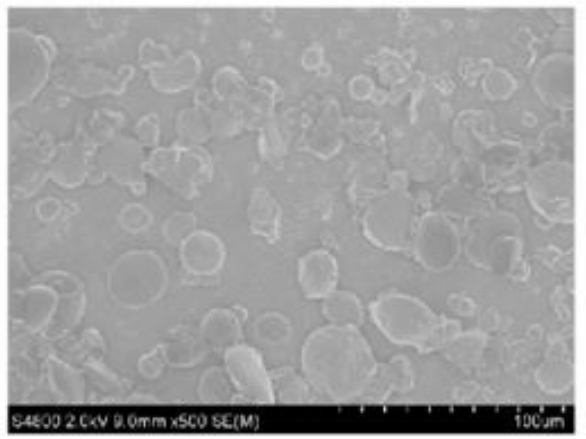

(G)

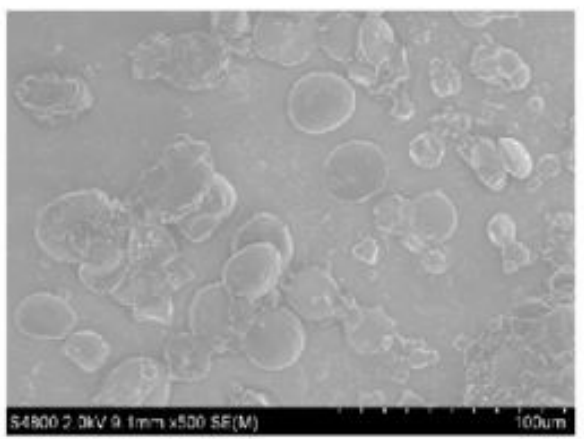

(H)

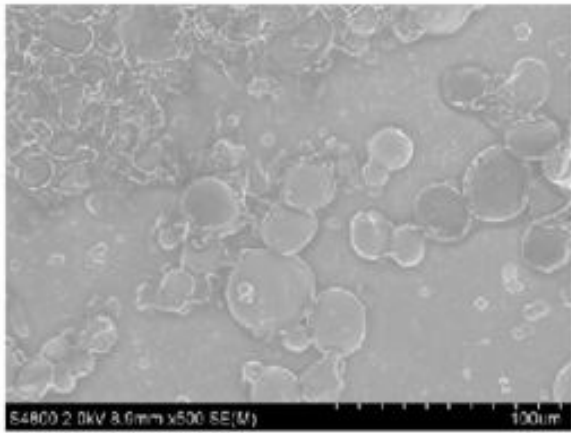

(I)

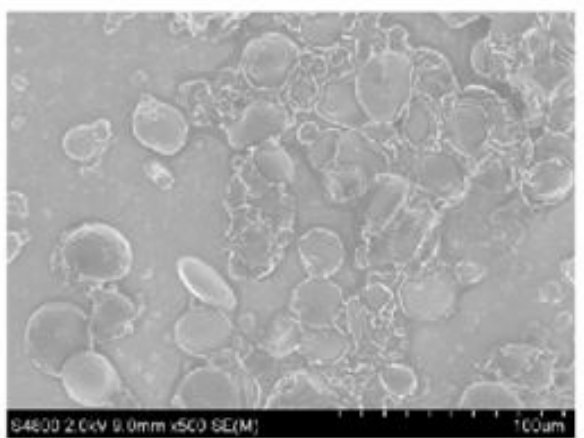

(J)

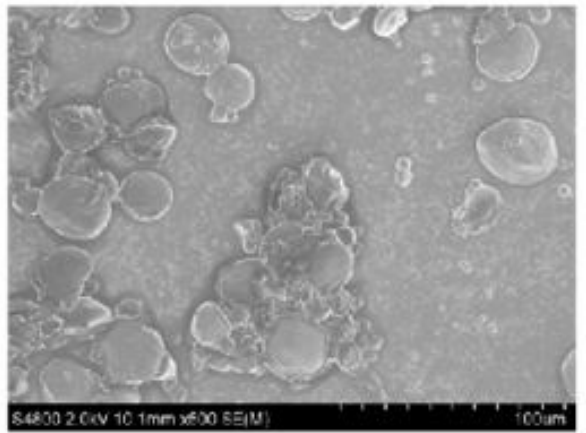

Figure 5. SEM image of low-fat moon-cake skin. 
Table 7. Sensory evaluation of low-fat moon-cake skin.

\begin{tabular}{|c|c|c|c|c|c|}
\hline Project & $\mathrm{C}$ & $\mathrm{T}_{1}$ & $\mathrm{~T}_{2}$ & $\mathrm{~T}_{3}$ & $\mathrm{~T}_{4}$ \\
\hline Shape & $9.24 \pm 0.29^{\mathrm{a}}$ & $9.28 \pm 0.24^{\mathrm{a}}$ & $9.14 \pm 0.42^{\mathrm{a}}$ & $9.19 \pm 0.28^{\mathrm{a}}$ & $8.05 \pm 0.14^{b}$ \\
\hline Color & $8.68 \pm 0.33^{a}$ & $8.96 \pm 0.33^{\mathrm{a}}$ & $8.75 \pm 0.43^{\mathrm{a}}$ & $8.47 \pm 0.26^{\mathrm{ab}}$ & $8.11 \pm 0.28^{b}$ \\
\hline Texture & $7.92 \pm 0.37^{\mathrm{a}}$ & $8.28 \pm 0.62^{\mathrm{a}}$ & $7.98 \pm 0.12^{\mathrm{a}}$ & $8.01 \pm 0.36^{\mathrm{a}}$ & $7.47 \pm 0.37^{\mathrm{b}}$ \\
\hline Taste and flavor & $7.88 \pm 0.53^{\mathrm{a}}$ & $8.49 \pm 0.37^{\mathrm{a}}$ & $8.03 \pm 0.54^{\mathrm{a}}$ & $7.74 \pm 0.62^{\mathrm{ab}}$ & $7.42 \pm 0.19^{b}$ \\
\hline Impurities & $4.12 \pm 0.21^{\mathrm{a}}$ & $4.06 \pm 0.41^{\mathrm{a}}$ & $4.32 \pm 0.19^{\mathrm{a}}$ & $4.17 \pm 0.22^{\mathrm{a}}$ & $3.93 \pm 0.34^{\mathrm{a}}$ \\
\hline overall acceptability & $4.17 \pm 0.30^{\mathrm{a}}$ & $4.27 \pm 0.35^{\mathrm{a}}$ & $3.97 \pm 0.51^{\mathrm{a}}$ & $4.13 \pm 0.28^{\mathrm{a}}$ & $3.31 \pm 0.17^{\mathrm{b}}$ \\
\hline Total score & $42.01 \pm 2.03^{\mathrm{a}}$ & $43.34 \pm 3.32^{\mathrm{a}}$ & $41.00 \pm 2.21^{\mathrm{a}}$ & $41.71 \pm 2.02^{\mathrm{a}}$ & $38.29 \pm 1.49^{b}$ \\
\hline
\end{tabular}

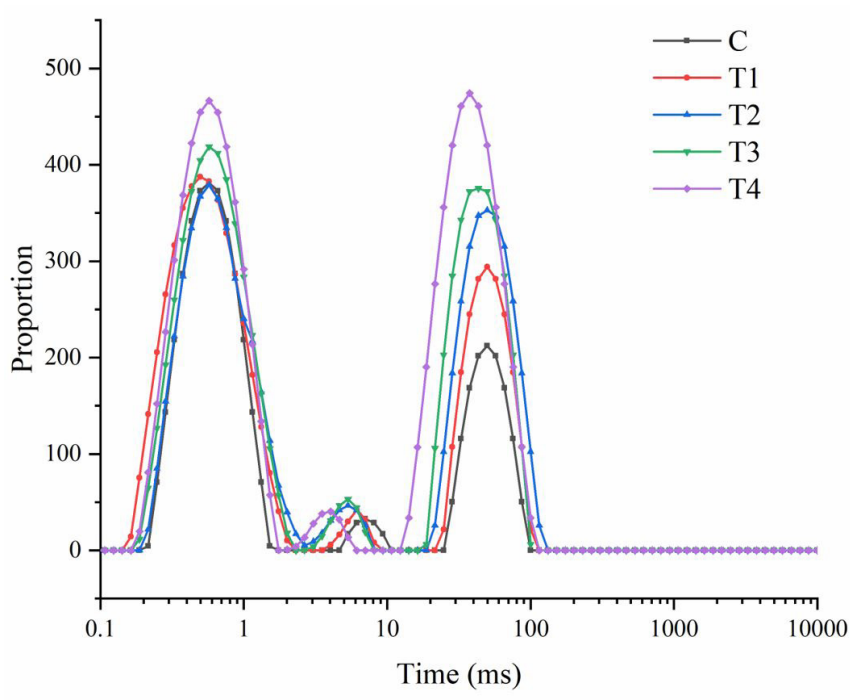

Figure 6. LF-NMR $\mathrm{T}_{2}$ inversion of low fat moon-cake skin.

Through the determination of nutritional components, when the oil replacement amount was $40 \%$, the fat content of lowfat moon-cake skin was $14.07 \% \pm 0.57 \%$, which decreased by $8.14 \%$ compared with that of the control group. No significant difference in protein content and ash content was observed compared with the control group $(\mathrm{P}>0.05)$.

\section{Conclusion}

The gel strength and water-holding capacity of gel prepared by the synergistic gelation agent G-SG had no significant difference from those of SG (P > 0.05). Results of rheological-property analysis showed that G-SG had strong hydrophobic interaction and formed a dense three-dimensional network structure. After being subjected to shear force, it was stable and suitable for fat substitute. When fat substitutes were applied to the processing technology of moon-cake skin, the brightness of low-fat moon-cake skin weakened, and red and yellow were enhanced. Hardness and adhesion gradually increased, whereas elasticity and chewability decreased. With increased oil substitution, the number of oil droplets in the sample gradually decreased, the volume of oil droplets gradually increased, and the flocculation effect strengthened. When the oil replacement amount was $40 \%$, no significant difference existed in texture characteristics and sensory score between the two groups $(\mathrm{P}>0.05)$. At this time, the fat content of low-fat moon-cake skin was $14.07 \% \pm 0.57 \%$, and the total sensory score was $41.71 \pm 2.02$. In conclusion, HCP can be used as a potential fat substitute and be applied to the processing technology of low-fat moon-cake skin. Its nutrition and function require further study.

\section{Conflict of interest}

All authors declared that there is no conflict of interest.

\section{Funding}

This work were supported by the National Key Research and Development Program of China (grant numbers 2017YFE122300) and the Heilongjiang Bayi Agricultural University Support Program for "San Zong" (grant numbers TDJH201906).

\section{Acknowledgment}

The authors gratefully acknowledge the financial support provided by all the funds.

\section{References}

Abboud, K. Y., Iacomini, M., Simas, F. F., \& Cordeiro, L. M. C. (2020). High methoxyl pectin from the soluble dietary fiber of passion fruit peel forms weak gel without the requirement of sugar addition. Carbohydrate Polymers, 246, 116616. http://dx.doi.org/10.1016/j. carbpol.2020.116616. PMid:32747256.

Abitbol, T., Mijlkovic, A., Malafronte, L., Stevanic, J. S., Larsson, P. T., \& Lopez-Sanchez, P. (2020). Cellulose nanocrystal/low methoxyl pectin gels produced by internal ionotropic gelation. Carbohydrate Polymers, 260, 117345. http://dx.doi.org/10.1016/j.carbpol.2020.117345. PMid:33712116.

Ajibade, B. O., \& Ijabadeniyi, O. A. (2019). Effects of pectin and emulsifiers on the physical and nutritional qualities and consumer acceptability of wheat composite dough and bread. Journal of Food Science and Technology, 56, 83-92.

Assoi, A., Konan, K., Agbo, G. N., Dodo, H., Holser, R., \& Wicker, L. (2017). Palmyra palm (Borassus aethiopum Mart.) fruits: novel raw materials for the pectin industry. Journal of the Science of Food and Agriculture, 97(7), 2057-2067. http://dx.doi.org/10.1002/jsfa.8010 PMid:27569539.

Attallah, O. A., \& Mamdouh, W. (2021). Development and optimization of pectin/chitosan magnetic sponge for efficient cationic dyes removal using Box-Behnken design. International Journal of Environmental Science and Technology, 18, 131-140. http://dx.doi.org/10.1007/ s13762-020-02828-4. 
Chunli, J., Yang, S. K., Weining, H., Guangwei, H. (2008). Sensory and instrumental assessment of Chinese moon cake: influences of almond flour, maltitol syrup, fat, and gums. Food Research International, 41(9), 930-936. https://doi.org/10.1016/j.foodres.2007.10.006.

Encalada, A. M. I., Pérez, C. D., Rossetti, L., Rojas, A. M., \& Fissore, E. N. (2020). Carrot pectin enriched fraction as a functional additive: antioxidant and gelling effects in a model spreadable chia oil-inwater emulsion. Food Hydrocolloids, 108, 106037. http://dx.doi. org/10.1016/j.foodhyd.2020.106037.

Figueroa, L. E., \& Genovese, D. B. (2018). Pectin gels enriched with dietary fibre for the development of healthy confectionery jams. Food Technology and Biotechnology, 56(3), 441-453. http://dx.doi. org/10.17113/ftb.56.03.18.5641 PMid:30510487.

Gokcen, A. E., Burcin, O. E., \& Oztop, M. H. (2021). Understanding the role of d-Allulose and soy protein addition in pectin gels. Journal of Applied Polymer Science, 138(8), 49885.

Güner, O. Z., Cam, C., Arabacioglu-Kocaaga, B., Batirel, S., \& Güner, F. S. (2018). Theophylline-loaded pectin-based hydrogels. I. effect of medium $\mathrm{p} \mathrm{H}$ and preparation conditions on drug release profile. Journal of Applied Polymer Science, 135(38), 46731. http://dx.doi. org/10.1002/app.46731.

Günter, E. A., Martynov, V. V., Belozerov, V. S., Martinson, E. A., \& Litvinets, S. G. (2020). Characterization and swelling properties of composite gel microparticles based on the pectin and $\kappa$-carrageenan. International Journal of Biological Macromolecules, 164, 2232-2239. http://dx.doi.org/10.1016/j.ijbiomac.2020.08.024. PMid:32771505.

Haddad, A. M. L., Ribotta, P., Armada, M., \& Goldner, M. C. (2019). Textural, pasting, and rheological behavior of starch-pectin-sucrose gels: relation with sensory perception. Starch, 71(9-10), 1800286. http://dx.doi.org/10.1002/star.201800286.

Huang, S., Tu, Z., Sha, X., Wang, H., Hu, Y., \& Hu, Z. (2020). Gelling properties and interaction analysis of fish gelatin-low-methoxyl pectin system with different concentrations of $\mathrm{Ca}^{2+}$. LWT, 132, 109826. http://dx.doi.org/10.1016/j.lwt.2020.109826.

Huang, T., Zhao, H., Fang, Y., Lu, J., Yang, W., Qiao, Z., Lou, Q., Xu, D., \& Zhang, J. (2019). Comparison of gelling properties and flow behaviors of microbial transglutaminase (MTGase) and pectin modified fish gelatin. Journal of Texture Studies, 50(5), 400-409. http://dx.doi.org/10.1111/jtxs.12405 PMid:31063585.

Kakino, Y., Hishikawa, Y., Onodera, R., Tahara, K., \& Takeuchi, H. (2017). Gelation factors of pectin for development of a powder form of gel, dry jelly, as a novel dosage form. Chemical \& Pharmaceutical Bulletin, 65(11), 1035-1044. http://dx.doi.org/10.1248/cpb.c1700447. PMid:29093290.

Kim, G. W., Pyo, M., \& Chung, S. H. (2020). Pectin lyase-modified red ginseng extract improves glucose homeostasis in high fat diet-fed mice. Journal of Ethnopharmacology, 249, 112384. http://dx.doi. org/10.1016/j.jep.2019.112384 PMid:31733309.

Li, C., Wu, X., Mu, D., Zhao, Y., Luo, S., Zhong, X., Jiang, S., Li, X., \& Zheng, Z. (2018). Effect of partial hydrolysis with papain on the characteristics of transglutaminase-crosslinked tofu gel. Journal of Food Science, 83(12), 3092-3098. http://dx.doi.org/10.1111/17503841.14403 PMid:30461022.

Li, X., Dong, Y., Guo, Y., Zhang, Z., Jia, L., Gao, H., Xing, Z., \& Duan, F. (2019). Okra polysaccharides reduced the gelling-required sucrose content in its synergistic gel with high-methoxyl pectin by microphase separation effect. Food Hydrocolloids, 95, 506-516. http://dx.doi.org/10.1016/j.foodhyd.2019.04.069.
Liu, H., Xu, X. M., \& Guo, S. D. (2008). Comparison of full-fat and low-fat cheese analogues with or without pectin gel through microstructure, texture, rheology, thermal and sensory analysis. International Journal of Food Science \& Technology, 43(9), 1581-1592. http://dx.doi.org/10.1111/j.1365-2621.2007.01616.x.

Maneerat, N., Tangsuphoom, N., \& Nitithamyong, A. (2017). Effect of extraction condition on properties of pectin from banana peels and its function as fat replacer in salad cream. Journal of Food Science and Technology, 54(2), 386-397. http://dx.doi.org/10.1007/s13197016-2475-6. PMid:28242938.

Méndez-Zamora, G., García-Macías, J. A., Santellano-Estrada, E., Chávez-Martínez, A., Durán-Meléndez, L. A., Silva-Vázquez, R., \& Quintero-Ramos, A. (2015). Fat reduction in the formulation of frankfurter sausages using inulin and pectin. Food Sci. Technol., 35(1), 25-31.

Moreira, H. R., Munarin, F., Gentilini, R., Visai, L., Granja, P. L., Tanzi, M. C., \& Petrini, P. (2014). Injectable pectin hydrogels produced by internal gelation: $\mathrm{pH}$ dependence of gelling and rheological properties. Carbohydrate Polymers, 103, 339-347. http://dx.doi. org/10.1016/j.carbpol.2013.12.057. PMid:24528738.

Naho, N., Yuki, F., Shiori, S., Shungo, S., Kaihei, O., Toshimichi, M., Emiko, O. (2021). Effects of treatment at a subzero temperature on $\mathrm{pH}$, water retention, and metabolites in spotted mackerel (Scomber australasicus) muscle. LWT, 154.https://doi.org/10.1016/j. lwt.2021.112591.

Ogutu, B., Kim, Y., Kim, D., Oh, S., Hong, D., \& Lee, Y. (2017). Optimization of maillard reaction between glucosamine and other precursors by measuring browning with a spectrophotometer. Preventive Nutrition and Food Science, 22(3), 211-215. PMid:29043219.

Paşcalău, V., Bogdan, C., Pall, E., Matroş, L., Pandrea, S., Suciu, M., Borodi, G., Iuga, C. A., Ştiufiuc, R., Topală, T., Pavel, C., Popa, C., \& Moldovan, M. L. (2020). Development of BSA gel/pectin/chitosan polyelectrolyte complex microcapsules for berberine delivery and evaluation of their inhibitory effect on Cutibacterium acnes. Reactive \& Functional Polymers, 147, 104457.

Peng, X., Yang, G., Shi, Y., Zhou, Y., Zhang, M., \& Li, S. (2020). BoxBehnken design based statistical modeling for the extraction and physicochemical properties of pectin from sunflower heads and the comparison with commercial low-methoxyl pectin. Scientific Reports, 10, 3595. http://dx.doi.org/10.1038/s41598-020-60339-1. PMid:32108167.

Sánchez-Alonso, I., Moreno, P., \& Careche, M. (2014). Low field nuclear magnetic resonance (LF-NMR) relaxometry in hake (Merluccius merluccius, L.) muscle after different freezing and storage conditions. Food Chemistry, 153, 250-257. http://dx.doi. org/10.1016/j.foodchem.2013.12.060. PMid:24491727.

Schröder, R., Clark, C. J., Sharrock, K., Hallett, I. C., \& MacRae, E. A. (2004). Pectins from the albedo of immature lemon fruitlets have high water binding capacity. Journal of Plant Physiology, 161(4), 371379. http://dx.doi.org/10.1078/0176-1617-01275. PMid:15128024.

Singh, V., Guizani, N., Al-Alawi, A., Claereboudt, M., \& Rahman, M. S. (2013). Instrumental texture profile analysis (TPA) of date fruits as a function of its physico-chemical properties. Industrial Crops and Products, 50, 866-873. http://dx.doi.org/10.1016/j.indcrop.2013.08.039.

Wan, L., Wang, H., Zhu, Y., Pan, S., Cai, R., Liu, F., \& Pan, S. (2019). Comparative study on gelling properties of low methoxyl pectin prepared by high hydrostatic pressure-assisted enzymatic, atmospheric enzymatic, and alkaline de-esterification. Carbohydrate Polymers, 
226, 115285. http://dx.doi.org/10.1016/j.carbpol.2019.115285. PMid:31582075.

Wang, L., Zhao, S., Liu, Y., \& Xiong, S. (2020). Quality characteristics and evaluation for sponge cakes made of rice flour. Journal of Food Processing and Preservation, 44(7), e14505. http://dx.doi.org/10.1111/jfpp.14505.

Wang, Y., Yang, Q., Li-Sha Y., \& Chen, H. (2021). Structural, gelation properties and microstructure of rice glutelin/sugar beet pectin composite gels: effects of ionic strengths. Food Chemistry, 346, 128956.

Yan, J., Chun, W., Qiu, W. Chen, T., Yang, Y., Wang, W., \& Zhang, H. (2021). Ultrasonic treatment at different $\mathrm{pH}$ values affects the macromolecular, structural, and rheological characteristics of citrus pectin. Food Chemistry, 341(Part 1), 128216. http://dx.doi. org/10.1016/j.foodchem.2020.128216. PMid:33032253.

Zhang, C., Zhu, X., Zhang, F., Yang, X., Ni, L., Zhang, W., Liu, Z., \& Zhang, Y. (2020). Improving viscosity and gelling properties of leaf pectin by comparing five pectin extraction methods using green tea leaf as a model material. Food Hydrocolloids, 98, 105246. http:// dx.doi.org/10.1016/j.foodhyd.2019.105246.

Zhang, H., Chen, J., Li, J., Wei, C., Ye, X., Shi, J., \& Chen, S. (2018). Pectin from Citrus Canning Wastewater as potential fat replacer in ice cream. Molecules, 23(4), 925. http://dx.doi.org/10.3390/ molecules23040925. PMid:29673153. 